\title{
Open-access publishing in times of crises: The future of scientific success lies in accessibility for all
}

\author{
Darshana Shah, PhD'
}

ABSTRACT

Author affiliations are

listed at the end of this

The COVID-19 crisis has been stressful and challenging for families and communities. I hope that you, your families, and your colleagues are safe and well. On behalf of the Marshall Journal of Medicine Editorial Board, I want to express my sincere appreciation to all of you who are on the front lines fighting the pandemic, trying to understand the pathophysiology of COVID-19, developing tools and treatment, or caring for the people affected by the virus. I am grateful for each and every one of you.

article.

Correspondence to: Darshana Shah, PhD Marshall University Joan C. Edwards School of Medicine shah@marshall.edu

\section{KEYWORDS}

Open Access Publishing

The COVID-19 crisis has been stressful and challenging for families and communities. I hope that you, your families, and your colleagues are safe and well. On behalf of the Marshall Journal of Medicine Editorial Board, I want to express my sincere appreciation to all of you who are on the front lines fighting the pandemic, trying to understand the pathophysiology of COVID-19, developing tools and treatment, or caring for the people affected by the virus. I am grateful for each and every one of you. As the scientific community has scrambled to keep up with emerging research, treatments, and guidelines in the wake of the COVID-19 crisis, open-science communication has emerged as a powerful tool for managing public health. Open science, an umbrella term for diverse strategies that seek external input and public engagement, is becoming critical to fighting COVID-19'. Scientists have needed to learn about COVID-19 at record speed while efficiently communicating findings to protect public health. Scientific research data offers key building blocks to create new scientific knowledge, and it is essential to leverage scientific innovations and support principles of openness and inclusiveness in processes that generate solutions to this, and other, severe health hazards. Researchers are increasingly turning to collaboration, crowd- sourcing, data sharing, and open-sourcing to tackle some of the most pressing problems in medicine ${ }^{2}$. Open-access, peer-reviewed journal articles are central to open science and the open-data and opensource movement, in which broader community participation is allowed via liberal copyright license terms. Open data involves sharing the data resultant from scientific inquiry with the broader research community. The significant change in open-access scholarly publishing likely stems directly from Plan S, an initiative that arose from an international group of research funders (Coalition S) ${ }^{3}$. Coalition $\mathrm{S}$ requires that beginning in 2021, scientific publications that result from research funded by public grants must be published in compliant open-access journals or platforms3. The unrestricted sharing of scientific papers during the coronavirus pandemic may have further hastened the shift toward more open-access publishing. Peer-reviewed, open-access journal articles offer immediate access to high-quality research, and the format enables the identification of authors and the dissemination of research across the globe in an instant without any cost to readers ${ }^{4}$.

Leading journals are moving to make content publicly available, and scientists believe the interplay of 
the ideas they generate is becoming easier to track ${ }^{2}$. Publishing your work in an open-access forum is beneficial for authors and readers, and can be accomplished in a variety of ways ${ }^{3}$. Publish in fully open-access, peer-reviewed journals, which are listed at the Directory of Open Access Journals (DOAJ). Work with your university library publishing service, and create an all-open journal or open-data resource. Publish in a journal that allows you to share your articles in an online scholarly repository for no additional fee . $^{5}$

COVID-19 has taught the scientific community that open access to information is imperative if we are to respond to crises efficiently and effectively. As new scientific challenges continue to threaten our society, we must pivot and respond appropriately, even if it means dismantling our traditional means of disseminating information. No longer is it acceptable for contemporary scientific knowledge to be passed around elite circles. Ensuring that relevant, timely scientific research is freely-available for all is critical to our community's future success against events that threaten our global health.

\section{AUTHOR AFFILIATIONS}

1. Marshall University Joan C. Edwards School of Medicine, Huntington, WV

\section{REFERENCES}

1. Tse EG, Klug DM, Todd MH. Open science approaches to COVID-19. F1000Res. 2020; 9:1043. Published 2020 Aug 25. doi:10.12688/f1000research.26084.1

2. Shaw DL. Is Open Science the Future of Drug Development? Yale J Biol Med. 2017 Mar 29;90(1):147-151. PMID: 28356902; PMCID: PMC5369032.

3. 'Plan $\mathrm{S}^{\prime}$ and 'cOAlition $\mathrm{S}^{\prime}$ - Accelerating the transition to full and immediate Open Access to scientific publications (coalition-s.org)

4. Shah, Darshana T. PhD (2020) "The New Decade of Scholarly Publishing," Marshall Journal of Medicine: Vol. 6: Iss. 1, Article 1.DOI: 10.33470/23799536.1264

5. Publishing, Scholarly Communication, and Open Access: Author's Rights. University Library website. Updated 22 June 2020. Accessed 24 Jan 2021. https://researchguides.uic.edu/sc 